Article

\title{
An Enzymatic Glucose Sensor Composed of Carbon-Coated Nano Tin Sulfide
}

\author{
Ren-Jei Chung *, An-Ni Wang and Shiuan-Ying Peng \\ Department of Chemical Engineering and Biotechnology, National Taipei University of Technology (Taipei Tech), \\ Taipei 10608, Taiwan; dai20020223@gmail.com (A.-N.W.); terrypntut@gmail.com (S.-Y.P.) \\ * Correspondence: rjchung@ntut.edu.tw; Tel.: +886-287728701
}

Academic Editor: Thomas Nann

Received: 5 January 2017; Accepted: 11 February 2017; Published: 15 February 2017

\begin{abstract}
In this study, a biosensor, based on a glucose oxidase $\left(\mathrm{GO}_{x}\right)$ immobilized, carbon-coated tin sulfide (SnS) assembled on a glass carbon electrode (GCE) was developed, and its direct electrochemistry was investigated. The carbon coated SnS (C-SnS) nanoparticle was prepared through a simple two-step process, using hydrothermal and chemical vapor deposition methods. The large reactive surface area and unique electrical potential of C-SnS could offer a favorable microenvironment for facilitating electron transfer between enzymes and the electrode surface. The structure and sensor ability of the proposed $\mathrm{GO}_{x} / \mathrm{C}-\mathrm{SnS}$ electrode were characterized using scanning electron microscopy (SEM), X-ray diffraction (XRD), Raman spectroscopy, UV-vis spectroscopy, Fourier transform infrared spectroscopy (FTIR), and cyclic voltammetry study (CV).
\end{abstract}

Keywords: hydrothermal; chemical vapor deposition; carbon coated SnS (C-SnS); enzymatic glucose sensor

\section{Introduction}

According to a global report on diabetes, published by the World Health Organization (WHO) in 2016 [1], more than 422 million adults (approximately) are living with diabetes, and its complications caused around 1.5 million deaths worldwide in 2012. Diabetes is a chronic disease; its syndrome is acknowledged by a high blood glucose $(>7.8 \mathrm{mM})$, due to insufficient control of hormones and endocrines in the human body. In order to prevent, or slow down the complications of diabetes, blood glucose must be regularly and accurately monitored. Biochemical tests are one of the most commonly-used techniques in detecting blood glucose, utilizing the oxidation of glucose and reduction of oxygen in blood in order to produce a linear current correlation with respect to glucose concentration [2-4]. Glucose biosensors, based on electrochemistry, can be divided into non-enzymatic and enzymatic types [5]. While the non-enzymatic type has great advantages, such as high sensitivity, high stability and the ability to work in extreme environments, such as in high temperatures and $\mathrm{pH}$ values, its specificity is limited and can be easily influenced by other interferents [5]. On the other hand, enzymatic sensors have high specificity and can be designed to fit individual chemicals, such as glucose oxidase $\left(\mathrm{GO}_{x}\right)[3,4,6-9]$.

The selection of electrode materials is another key factor in order to improve performance by providing a large reaction area and a favorable microenvironment to facilitate electron transfer between enzymes and the electrode surface. More recently, the phase stability, band-structure, and optical properties of SnS have been studied intensively [10-14], and SnS holds an adjustable hole concentration, depending on the growth temperature and smaller band gap $(\sim 1.43 \mathrm{eV})$ compared with $\mathrm{SnS}_{2}(2.18-2.44 \mathrm{eV})$ [15]. Hence, $\mathrm{SnS}$ is suitable for use as a biosensor material. On the other hand, amorphous carbon has several interesting properties, such as good thermal conductivity, good mechanical strength, attrition resistance, is chemically inert, and possesses a satisfactory 
biocompatibility. The atomic structure is composed of a combination of $\mathrm{sp}^{2}$ and $\mathrm{sp}^{3}$ for carbon, which contributes to the electrical, optical, and mechanical properties [16,17]. Thereby, we propose a new enzymatic glucose biosensor, using carbon-coated $\mathrm{SnS}$ and $\mathrm{GO}_{x}$. In this study, we investigated the enzymatic glucose sensor, in which there is direct electron exchange between the enzyme and the electrode in order to complete the catalytic cycle. We prepared carbon-coated SnS (C-SnS) nanoflake powder using a simple two-step process, consisting of hydrothermal and chemical vapor deposition (CVD) methods. The structure and composition were identified using X-ray diffraction (XRD) and Raman spectroscopy, and the performance of glucose oxidase $\left(\mathrm{GO}_{x}\right)$ on the C-SnS sensor was investigated by cyclic voltammetry study.

\section{Experimental Procedures}

The carbon-coated SnS (C-SnS) powder was synthesized using a two-step process. First, the $\mathrm{SnS}_{2}$ nanoflake was fabricated via the hydrothermal synthesis method in order to serve as the base material. An amount of $0.351 \mathrm{~g}$ of $\mathrm{SnCl}_{4}$, and $0.3 \mathrm{~g}$ of $\mathrm{C}_{2} \mathrm{H}_{5} \mathrm{NS}$, were added into $70 \mathrm{~mL}$ of deionized water with $0.5 \mathrm{M} \mathrm{NaOH}_{(\mathrm{aq})}$ to adjust the $\mathrm{pH}$ value to 10.5 ; after stirring for $30 \mathrm{~min}$, the solution was then heated to $200{ }^{\circ} \mathrm{C}$ and maintained for $12 \mathrm{~h}$. In the following step, the precipitated $\mathrm{SnS}_{2}$ powder was then centrifuged, thoroughly washed, and dried at $80^{\circ} \mathrm{C}$ for $12 \mathrm{~h}$. A chemical vapor deposition (CVD) system was utilized for carbon coating, where ethanol was the source of carbon and was carried by Ar gas with a $50 \mathrm{sccm}$ flow rate at $400{ }^{\circ} \mathrm{C}$ for $1 \mathrm{~h}$. After carbon coating, the C-SnS was formed with a thick carbon layer; the possible formation mechanism for this will be discussed in this work. The structure of the as-synthesized $\mathrm{SnS}_{2}$ and C-SnS powders were characterized by X-ray diffraction and the $\theta / 2 \theta$ scan ranged from $10^{\circ}$ to $60^{\circ}$, where the $\mathrm{SnS}_{2}$ and $\mathrm{SnS}$ were identified according to joint committee on powder diffraction standards (JCPDS) cards No. 83-1705 and 75-0925, respectively. The microstructure of the $\mathrm{SnS}_{2}$ and C-SnS powders were observed from SEM topographies and selected area electron diffraction (SAED) patterns. Raman spectroscopy was used in order to identify the carbon coating of the C-SnS.

The material stacking and assembling details of the $\mathrm{GO}_{x} / \mathrm{C}-\mathrm{SnS} / \mathrm{GC}$ electrode are as follows: $1 \mathrm{mg}$ C-SnS powder and $1 \mathrm{mg} \mathrm{GO} x$ were mixed, separately, with $1 \mathrm{~mL}$ of deionized water, and then $5 \mu \mathrm{L}$ of the individual solutions were transferred onto a polished, glassy carbon (GC) electrode on the order of C-SnS, and then $\mathrm{GO}_{x}$, and dried for $10 \mathrm{~min}$ at each step. Finally, $5 \mu \mathrm{L}$ of $5 \%$ Nafion (Sigma-Aldrich) solution was used to coat and protect the $\mathrm{GO}_{x}$ layer. The as-prepared electrode was immediately stored in a moisture resistant cabinet at room temperature, and the humidity was controlled below $50 \%$. Prior to the glucose detection test, the adhesion of $\mathrm{GO}_{x}$ onto C-SnS was examined using FTIR (HORIBA, Kyoto, Japan) and UV-vis spectroscopies (Agilent Technologies, Santa Clara, CA, USA). Three different working electrodes were used in order to compare with the $\mathrm{GO}_{x} / \mathrm{SnS} / \mathrm{GCE}$ sensor; bare glassy carbon (GCE), C-SnS coating on GCE (C-SnS/GCE), and $\mathrm{GO}_{x}$ on $\mathrm{GCE}\left(\mathrm{GO}_{x} / \mathrm{GCE}\right)$ electrodes. As for the reference and auxiliary electrodes, the commercial $\mathrm{Hg} / \mathrm{Hg}_{2} \mathrm{Cl}_{2}$ reference electrode and the platinum electrode were utilized, respectively. A potentiostat (CHI611E) was used for $\mathrm{CV}$ scanning and the potential scan ranged from $-0.2 \mathrm{~V}$ to $-0.7 \mathrm{~V}$. First, the $\mathrm{CV}$ profiles of the different working electrodes were assessed in $0.1 \mathrm{M}$ phosphate-buffered saline $(\mathrm{pH}=6.0)$ in order to demonstrate the analytical performance of the $\mathrm{GO}_{x} / \mathrm{C}$-SnS/GCE sensor. In order to further investigate the sensitivity and limits of the $\mathrm{GO}_{x} / \mathrm{C}-\mathrm{SnS} / \mathrm{GCE}$ glucose detector, different scanning speeds, from $50 \mathrm{mV} / \mathrm{s}$ to $300 \mathrm{mV} / \mathrm{s}$, pH values, from 4 to 7 , and glucose concentrations, from 0 to $1 \mathrm{mM}$, were used. Furthermore, the current vs. time curve of the $\mathrm{GO}_{x} / \mathrm{C}$-SnS/GCE electrode was measured at $-0.41 \mathrm{~V}$ in $0.1 \mathrm{M}$ phosphate-buffered saline $(\mathrm{pH}=6.0)$ with respect to different glucose concentrations, from which the graph of corresponding current vs. glucose concentration was plotted and calibrated. Finally, the amperometric response of the $\mathrm{GO}_{x} / \mathrm{C}$-SnS/GCE electrode to $0.1 \mathrm{mM}$ glucose, as well as $0.1 \mathrm{mM}$ interferents of citric acid (CA) and uric acid (UA), were measured in order to investigate the specificity in glucose censoring. In order to ensure the reproducibility, the fabrication has been carried out by different researchers in our group with triplicates, and several different biosensors, based on the proposed C-SnS, are still being investigated. 


\section{Results and Discussion}

The structures of the as-synthesized $\mathrm{SnS}_{2}$ and carbon-coated powders were observed from SEM images and XRD patterns, as depicted in Figures 1 and 2, respectively. The $\mathrm{SnS}_{2}$ nanoflake powder size, observed from the SEM image, shows an average size of $500 \mathrm{~nm}$ in width with a thickness of $75 \mathrm{~nm}$ (Figure 1a); after carbon coating, the particle size increases dramatically and formed a laminar microstructure with a thickness of $200 \mathrm{~nm}$ (Figure 1b). From the XRD patterns in Figure 2a,b, corresponding to the as-synthesized $\mathrm{SnS}_{2}$ and the carbon-coated powders, both structures fit well with the JCPDS cards corresponding to hexagonal $\mathrm{SnS}_{2}$ and orthorhombic $\mathrm{SnS}$ crystalline structures; in addition, both possessed excellent crystallinity. The average domain sizes were $36 \mathrm{~nm}$ and $17 \mathrm{~nm}$ for $\mathrm{SnS}_{2}$ and $\mathrm{SnS}$, respectively, calculated by the full-width-half-maximum (FWHM) at each diffraction peak using the Scherrer equation [18], and the results indicate an improvement in crystallinity from $\mathrm{SnS}_{2}$ to $\mathrm{SnS}$. A small diamond carbon peak around $44^{\circ}$ was found in Figure $2 \mathrm{~b}$ and the existence of carbon can be further confirmed from the Raman spectrum (Figure 3), in which the D and G bands of carbon with $\mathrm{I}(\mathrm{D}) / \mathrm{I}(\mathrm{G}) \sim 1$ appeared after carbon coating, while the Raman signal of $\mathrm{SnS}_{2}$ disappeared. The results of the Raman spectrum are consistent with those of the XRD patterns (Figure 2).

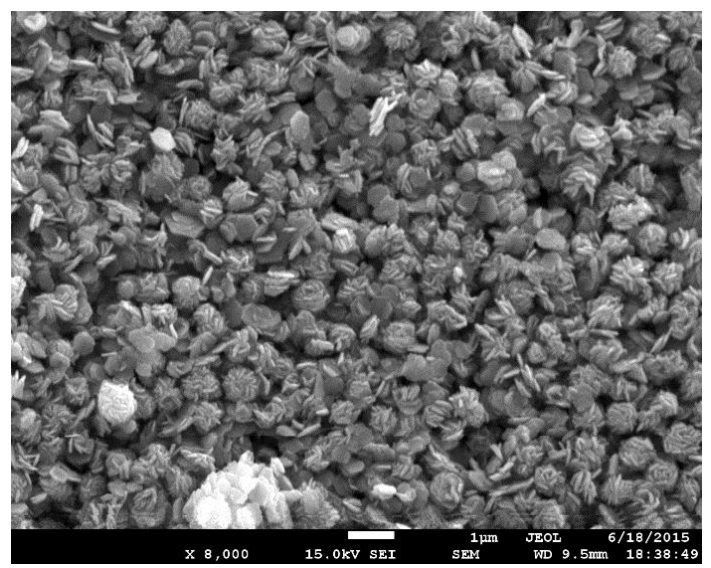

(a)

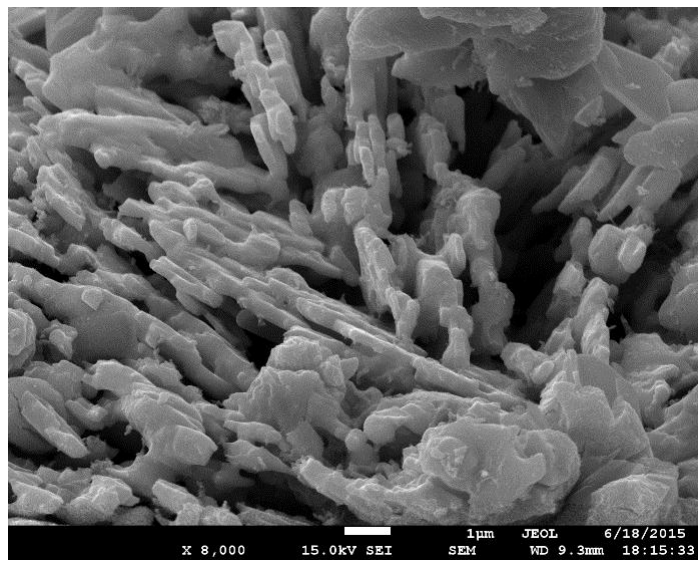

(b)

Figure 1. Scanning electron microscopy (SEM) images of (a) $\mathrm{SnS}_{2}$ and (b) carbon-coated tin sulfide (SnS) powders.

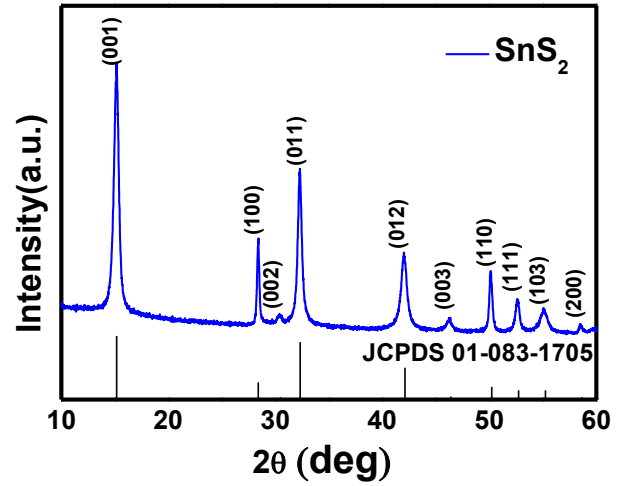

(a)

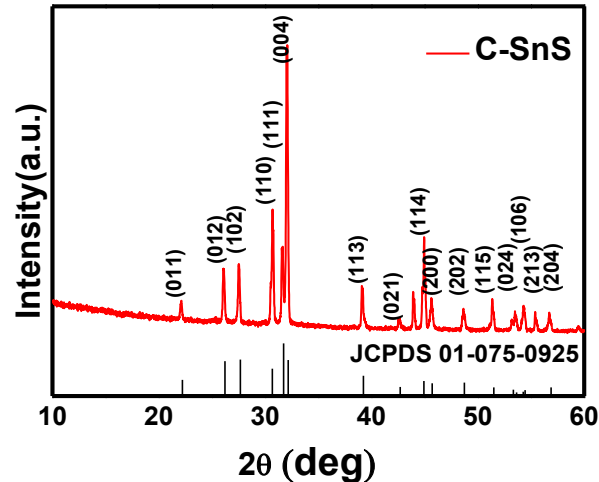

(b)

Figure 2. X-ray diffraction (XRD) $\theta / 2 \theta$ scan of (a) $\mathrm{SnS}_{2}$ and (b) carbon-coated SnS powders. 


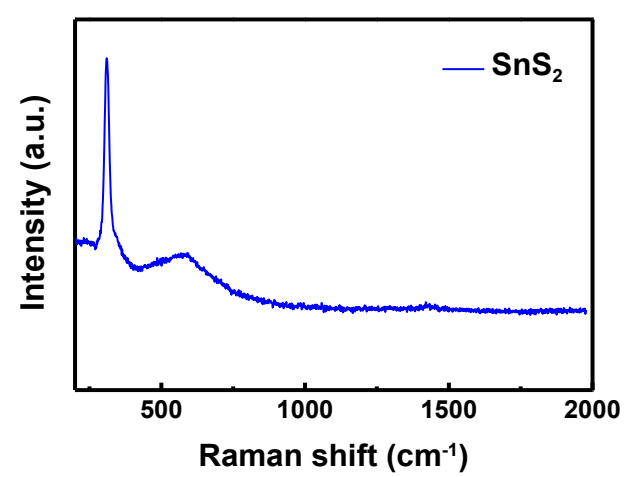

(a)

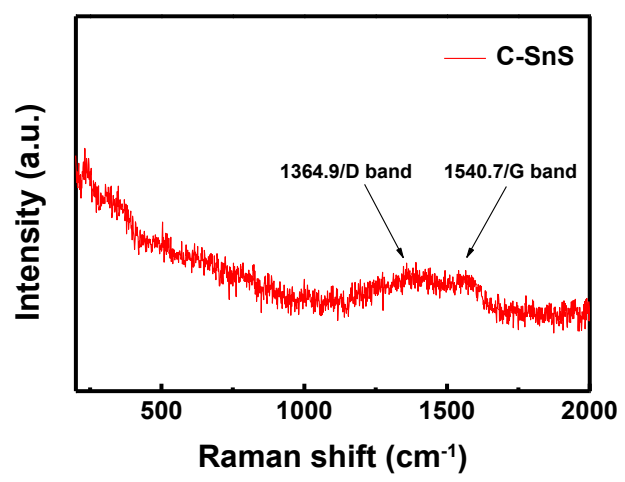

(b)

Figure 3. Raman spectrums of (a) $\mathrm{SnS}_{2}$ and (b) carbon-coated $\mathrm{SnS}$ powders.

The transformation from $\mathrm{SnS}_{2}$ to $\mathrm{SnS}$ could be due to the phase stability of $\mathrm{SnS}_{x}$ during the CVD process at $400{ }^{\circ} \mathrm{C}$ and also the reactive carbon gas environment $[10,19]$. According to the ab initio calculations by Burton et al. [19] and Vidal et al. [10], the SnS Pnma structure should be a preferable phase at $400{ }^{\circ} \mathrm{C}$, which is consistent with our XRD and Raman observations. The excessive $\mathrm{S}$ during the phase transformation may assist the growth of amorphous hydrogenated carbon sulfur (a-C:H:S), and, thus, a clear D band was observed [16]. The enlarged laminar particle size and finer crystalline domain of SnS suggest that the SnS crystals were embedded in a preferentially-grown amorphous carbon, where the carbon layer grows faster along the surface (1-100) of the $\mathrm{SnS}_{2}$ nanoflake. The edge surface (1-100) of hexagonal $\mathrm{SnS}_{2}$ consisted of layered $\mathrm{S}$ and $\mathrm{Sn}$ atoms, which was able to promote the growth of a-C:H:S [16]. In sum, an obvious structural and compositional transformation, from hexagonal $\mathrm{SnS}_{2}$ to orthorhombic SnS, embedded in amorphous carbon with an improvement of crystallinity, could be achieved using a simple two-step synthesis process.

Prior to the glucose detection test, FTIR and UV-vis spectroscopies were used in order to examine the adhesion of $\mathrm{GO}_{x}$ onto C-SnS, and the results are shown in Figures 4 and 5. Without the $\mathrm{GO}_{x}$ layer, the bare C-SnS did not react to FTIR and UV-vis due to the large wavelength compared to the lattice parameters of carbon and SnS. With respect to $\mathrm{GO}_{x}$, the Amide I and II bands can be observed from the FTIR pattern at $1537 \mathrm{~cm}^{-1}$ and $1608 \mathrm{~cm}^{-1}$ (Figure 4); additionally, the polypeptide chains at $276 \mathrm{~nm}$ and the oxidized form of the flavin groups in the proteins at 379 and $452 \mathrm{~nm}$ are also shown in the UV-vis pattern (Figure 5). From the FTIR and UV-vis patterns, the combination $\mathrm{GO}_{x}$ on C-SnS shows the same characteristic signals as those mentioned above, indicating that the structure and activity of $\mathrm{GO}_{x}$ remain the same in C-SnS.

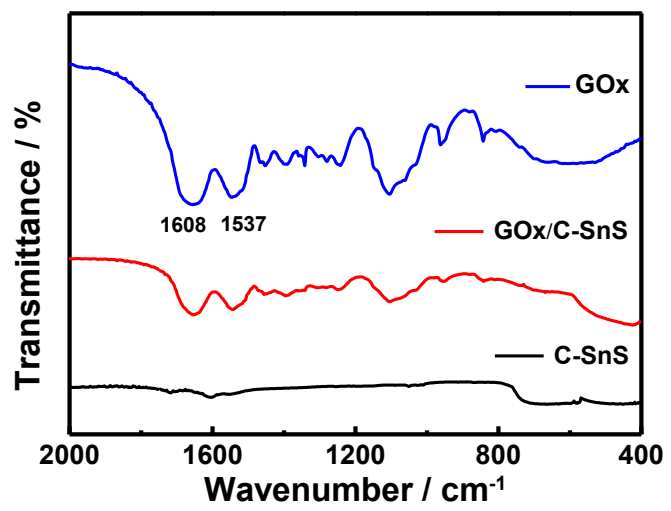

Figure 4. Fourier transform infrared spectroscopy (FTIR) of carbon-coated SnS (C-SnS), glucose oxidase $\left(\mathrm{GO}_{x}\right)$, and $\mathrm{GO}_{x}$ on C-SnS. 


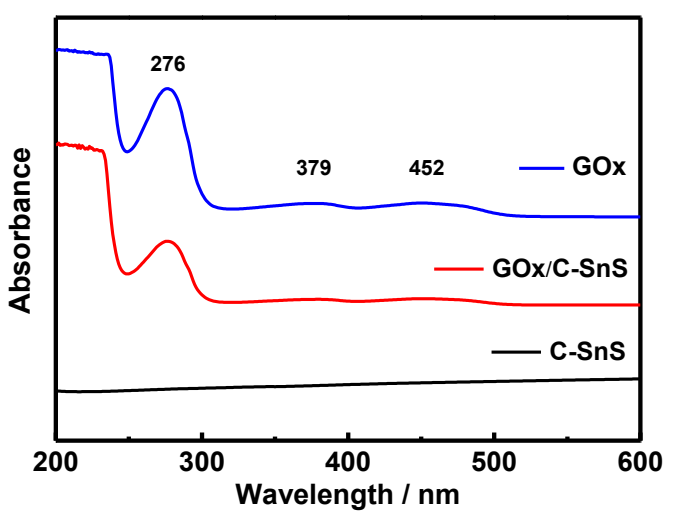

Figure 5. UV-vis spectroscopy of carbon-coated $\mathrm{SnS}(\mathrm{C}-\mathrm{SnS})$, glucose oxidase $\left(\mathrm{GO}_{x}\right)$, and $\mathrm{GO}_{x}$ on C-SnS.

The results of the CV scans, using four different working electrodes, are shown in Figure 6. By adding C-SnS to GCE, the overall current range increases, but there is no obvious redox behavior. On the other hand, $\mathrm{GO}_{x}$ shows a symmetric reduction and oxidation path, indicating that the redox behavior of $\mathrm{GO}_{x}$ is a reversible reaction. With the assistance of C-SnS, the peak current of both the reduction and oxidation parts increased two times, and the applied potential was $-0.41 \mathrm{~V}$, which is comparable to results from the literature [20]. Hence, the $\mathrm{GO}_{x} / \mathrm{C}-\mathrm{SnS} / \mathrm{GCE}$ electrode shows a good redox behavior and, therefore, the stacking can serve as a glucose sensor.

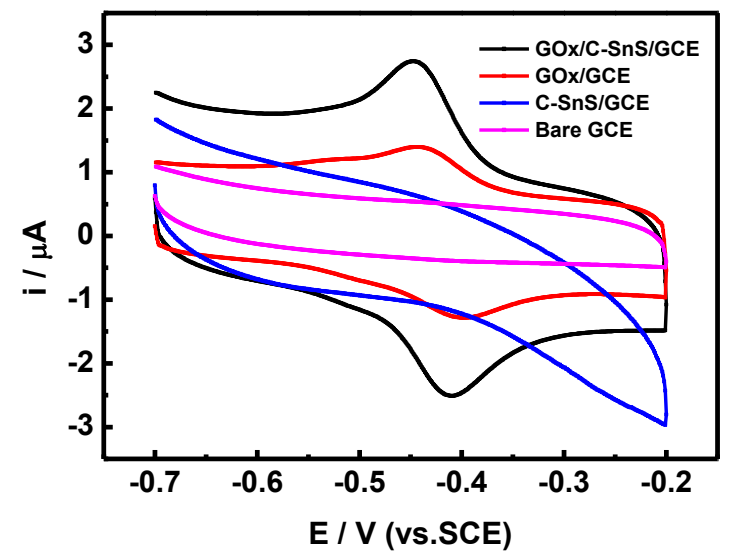

Figure 6. The cyclic voltammetry $(\mathrm{CV})$ profiles of different working electrodes were used to compare with the $\mathrm{GO}_{x}$ /SnS/GCE sensor, including bare glassy carbon electrode (GCE), C-SnS coating on GC (C-SnS/GCE), and $\mathrm{GO}_{x}$ on GC (GO $\left.\mathrm{GO}_{x} / \mathrm{GCE}\right)$ electrodes. The CV scan was carried out in $0.1 \mathrm{M}$ PBS at a scan rate of $100 \mathrm{mV} / \mathrm{s}$.

In order to calculate the electron transfer rate constant $(\mathrm{Ks})$, the potential $\left(\Delta E_{\mathrm{p}}\right)$ difference between the reduction and oxidation was recorded using different scanning speeds (Figure 7), and calculated using Laviron's equation [21]. The Ks of our proposed sensor stacking is $7.461 \mathrm{~s}^{-1}$, which is two times higher than those of similar glucose sensors $\left(\mathrm{SnS}_{2} / \mathrm{GO}_{x} / \mathrm{GCE}\right)$, proposed by Yang et al., which were measured at $3.68 \mathrm{~s}^{-1}$ [20]. Furthermore, the scanning rate showed a linear correlation with the redox current. We also utilized CV scans at different $\mathrm{pH}$ values (Figure 8) in order to optimize the sensing conditions. As the $\mathrm{pH}$ value decreased from 7 to 4 , which is the working $\mathrm{pH}$ value of $\mathrm{GO}_{x}$, the reduction peak moved forward to a lower potential, and the corresponding current also decreased. The optimized response current occurred at $\mathrm{pH}=7$, which is the same $\mathrm{pH}$ value as that human blood; hence, the proposed $\mathrm{GO}_{x} / \mathrm{C}$-SnS/GCE sensor shows an excellent advantage in practical usage. 


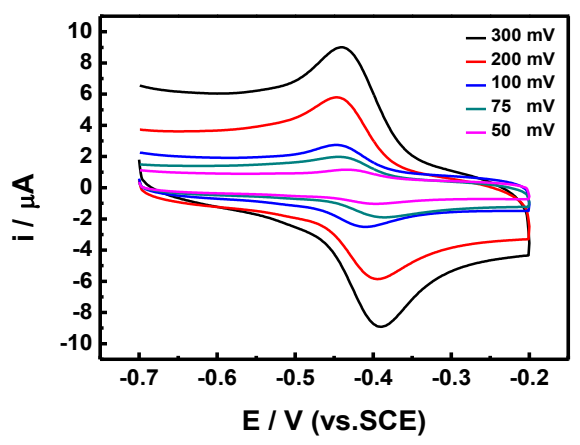

(a)

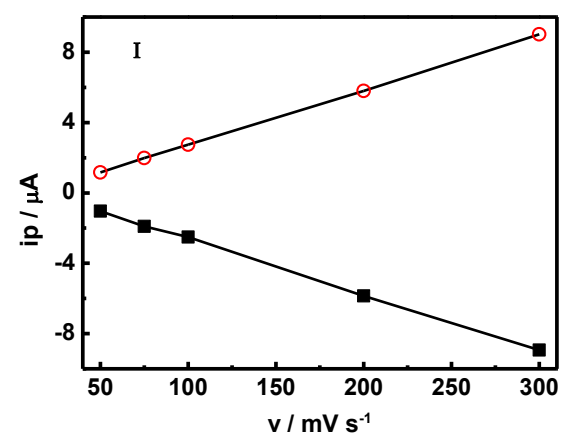

(b)

Figure 7. (a) CV profiles of the $\mathrm{GO}_{x} / \mathrm{SnS} / \mathrm{GCE}$ sensor under different scan rates and (b) the resultant oxidation and reduction plots.

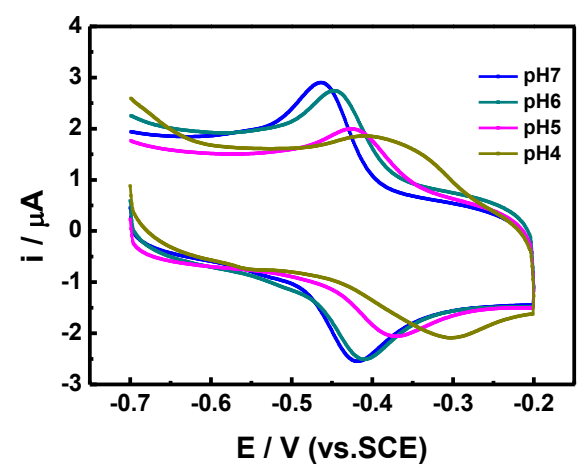

(a)

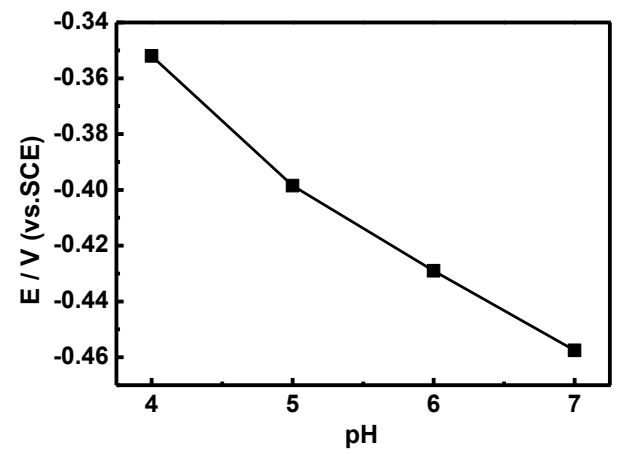

(b)

Figure 8. (a) $\mathrm{CV}$ profile of the $\mathrm{GO}_{x} / \mathrm{SnS} / \mathrm{GCE}$ sensor under different $\mathrm{pH}$ values, and (b) the linear plotting of the $\mathrm{E} / \mathrm{V}$ vs. $\mathrm{pH}$ values.

Figure 9 shows the sensitivity of the $\mathrm{GO}_{x} / \mathrm{C}-\mathrm{SnS} / \mathrm{GCE}$ sensor with respect to different glucose concentrations. According to the results of triplicates, the relative standard deviation (RSD) was less than $5.2 \%$ calculated from the current response of freshly prepared electrodes. The results convinced that the fabrication method was highly reproducible comparing with reported enzymatic and non-enzymatic glucose sensors [22,23]. A linear correlation, from 0.03 to $0.7 \mathrm{mM}$, can be found in glucose concentrations, and the sensitivity was $43.9 \mathrm{~mA} \cdot \mathrm{M}^{-1} \cdot \mathrm{cm}^{-2}$, roughly six times that found in Yang's work, using $\mathrm{SnS}_{2}$ [8]. Since human blood always contains different hormones and chemicals, which can interfere glucose sensor detection, an amperometric test was carried out using CA and UA, as depicted in Figure 10. Although the reactions are not clear, only a minor reaction occurred with the two interferents, which are in an acceptable and distinguishable response range. The amperometric response of the $\mathrm{GO}_{x} / \mathrm{SnS} / \mathrm{GCE}$ electrode demonstrates an acceptable selectivity to glucose. For enzymatic glucose sensor, it is reported that the retention of the original response may drop to less than $76 \%$ within seven days [24]. Furthermore, long-term stability was studied, and the results are provided in Figure 11. A stable and reproducible current over seven days was observed in our investigation. The presently commercialized glucose sensors are designed for blood samples. The users have to use lancet or syringe to collect blood from finger pricking or phlebotomizing. Noninvasive routes for glucose monitoring are highly expected to prevent these disadvantages. Thus, succedaneous body fluid samples such as urine, tear or saliva become prevailing targets for novel glucose sensor design. Proportional to blood glucose, however, they have relatively low glucose content [25]. A more sensitive glucose sensor with lower detection limit is required, and the developed sensor in this study will benefit. As to human blood, nevertheless, lower detection range needs fewer samples with proper dilute design on the system. 


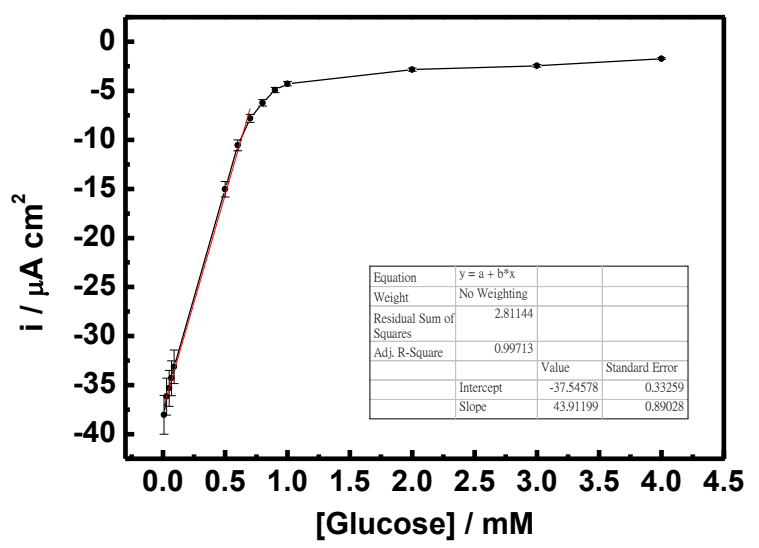

Figure 9. Current per unit area vs. glucose concentration of the $\mathrm{GO}_{x} / \mathrm{SnS} / \mathrm{GCE}$ sensor.

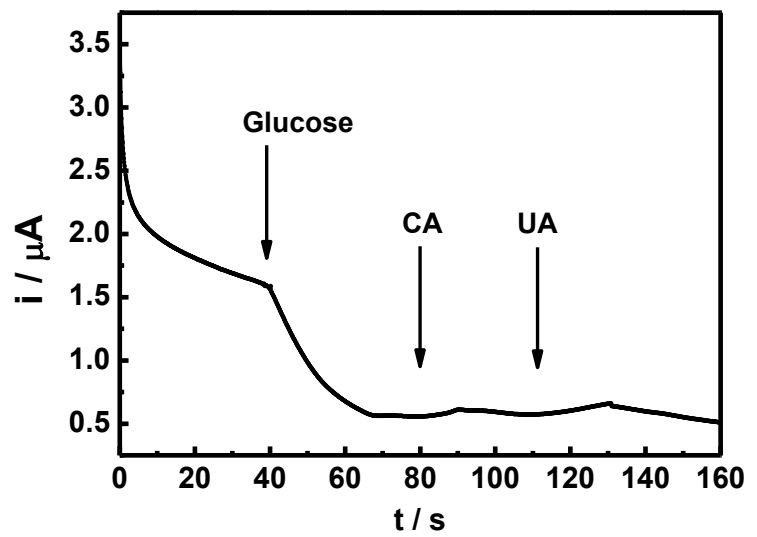

Figure 10. Amperometric response of the $\mathrm{GO}_{x} / \mathrm{SnS} / \mathrm{GCE}$ electrode to $0.1 \mathrm{mM}$ glucose, as well as $0.1 \mathrm{mM}$ interferents of uric acid (UA) and citric acid (CA).

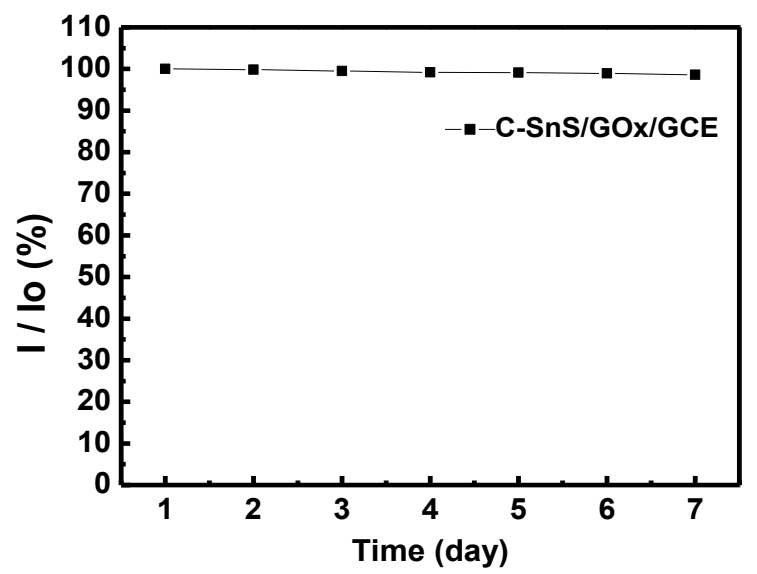

Figure 11. The performance stability of the C-SnS/GO $x /$ GCE sensor for 7 days, where $0.1 \mathrm{mM}$ glucose was used.

\section{Conclusions}

In this work, we reported a C-SnS nanoparticle powder with a laminar structure for use in enzymatic glucose sensor applications via a simple two-step synthesis process, using hydrothermal and chemical vapor deposition methods. The preparation of the proposed sensor is easy and cost-efficient. The fast electron transformation rate $\left(\mathrm{Ks}=7.46 \mathrm{~s}^{-1}\right)$, high sensitivity $\left(43.9 \mathrm{~mA} \cdot \mathrm{M}^{-1} \cdot \mathrm{cm}^{-2}\right)$, linear range from 0.03 to $0.7 \mathrm{mM}$ glucose, and acceptable selectivity show promising development potentials for glucose sensing. 
Acknowledgments: The authors are grateful for the financial support of this research by the Ministry of Science and Technology of the Republic of China, under Grant No. MOST 105-2221-E-027-028.

Author Contributions: Ren-Jei Chung organized and supervised the work; An-Ni Wang wrote the article and analyzed part of the data; Shiuan-Ying Peng performed the experiments, measurements, and data analyses.

Conflicts of Interest: The authors declare no conflicts of interest.

\section{References}

1. NCD Risk Factor Collaboration. Worldwide trends in diabetes since 1980: A pooled analysis of 751 population-based studies with 4.4 million participants. Lancet 2016, 387, 1513-1530.

2. Hsu, C.W.; Su, F.C.; Peng, P.Y.; Young, H.T.; Liao, S.; Wang, G.J. Highly sensitive non-enzymatic electrochemical glucose biosensor using a photolithography fabricated micro/nano hybrid structured electrode. Sens. Actuators B 2016, 230, 559-565. [CrossRef]

3. Wu, B.; Hou, S.; Miao, Z.; Zhang, C.; Ji, Y. Layer-by-layer self-assembling gold nanorods and glucose oxidase onto carbon nanotubes functionalized sol-gel matrix for an amperometric glucose biosensor. Nanomaterials 2015, 5, 1544-1555. [CrossRef]

4. Kong, F.Y.; Gu, S.X.; Li, W.W.; Chen, T.T.; Xu, Q.; Wang, W. A paper disk equipped with graphene/polyaniline/Au nanoparticles/glucose oxidase biocomposite modified screen-printed electrode: Toward whole blood glucose determination. Biosens. Bioelectron. 2014, 56, 77-82. [CrossRef] [PubMed]

5. Toghill, K.E.; Compton, R.G. Electrochemical non-enzymatic glucose sensors: A perspective and an evaluation. Int. J. Electrochem. Sci. 2010, 5, 1246-1301.

6. Li, J.; Yang, Z.; Tang, Y.; Zhang, Y.; Hu, X. Carbon nanotubes-nanoflake-like $\mathrm{SnS}_{2}$ nanocomposite for direct electrochemistry of glucose oxidase and glucose sensing. Biosens. Bioelectron. 2013, 41, 698-703. [CrossRef] [PubMed]

7. Yang, Z.; Huang, X.; Zhang, R.; Li, J.; Xu, Q.; Hu, X. Novel urchin-like $\mathrm{In}_{2} \mathrm{O}_{3}$-chitosan modified electrode for direct electrochemistry of glucose oxidase and biosensing. Electrochim. Acta 2012, 70, 325-330. [CrossRef]

8. Yang, Z.; Ren, Y.; Zhang, Y.; Li, J.; Li, H.; Hu, X.H.; Xu, Q. Nanoflake-like SnS 2 matrix for glucose biosensing based on direct electrochemistry of glucose oxidase. Biosens. Bioelectron. 2011, 26, 4337-4341. [CrossRef] [PubMed]

9. Oztekin, Y.; Krikstolaityte, V.; Ramanaviciene, A.; Yazicigil, Z.; Ramanavicius, A. 1,10-phenanthroline derivatives as mediators for glucose oxidase. Biosens. Bioelectron. 2010, 26, 267-270. [CrossRef] [PubMed]

10. Vidal, J.; Lany, S.; d'Avezac, M.; Zunger, A.; Zakutayev, A.; Francis, J.; Tate, J. Band-structure, optical properties, and defect physics of the photovoltaic semiconductor SnS. Appl. Phys. Lett. 2012, 100, 032104. [CrossRef]

11. Lorenz, T.; Joswig, J.-O.; Seifert, G. Combined SnS@SnS 2 double layers: Charge transfer and electronic structure. Semicond. Sci. Tech. 2014, 29, 064006. [CrossRef]

12. Chen, X.; Hou, Y.; Zhang, B.; Yang, X.H.; Yang, H.G. Low-cost SnS $x$ counter electrodes for dye-sensitized solar cells. Chem. Commun. 2013, 49, 5793-5795. [CrossRef] [PubMed]

13. Koteeswara Reddy, N.; Devika, M.; Gopal, E.S.R. Review on Tin (II) sulfide (SnS) material: synthesis, properties, and applications. Crit. Rev. Solid State 2015, 40, 359-398. [CrossRef]

14. Gou, X.L.; Chen, J.; Shen, P.W. Synthesis, characterization and application of $\operatorname{SnS}_{x}(x=1,2)$ nanoparticles. Mater. Chem. Phys. 2005, 93, 557-566. [CrossRef]

15. Shi, W.; Huo, L.; Wang, H.; Zhang, H.; Yang, J.; Wei, P. Hydrothermal growth and gas sensing property of flower-shaped $\mathrm{SnS}_{2}$ nanostructures. Nanotechnology 2006, 17, 2918-2924. [CrossRef]

16. Filik, J.; Lane, I.M.; May, P.W.; Pearce, S.R.J.; Hallam, K.R. Incorporation of sulfur into hydrogenated amorphous carbon films. Diam. Relat. Mater. 2004, 13, 1377-1384. [CrossRef]

17. Xu, S.; Tay, B.K.; Tan, H.S.; Zhong, L.; Tu, Y.Q.; Silva, S.R.P.; Milne, W.I. Properties of carbon ion deposited tetrahedral amorphous carbon films as a function of ion energy. J. Appl. Phys. 1996, 79, 7234-7240. [CrossRef]

18. Scherrer, P. The space grid of aluminium. Phys. Z 1918, 19, 23-27.

19. Burton, L.A.; Walsh, A. Phase stability of the earth-abundant tin sulfides $\mathrm{SnS}, \mathrm{SnS}_{2}$, and $\mathrm{Sn}_{2} \mathrm{~S}_{3}$. J. Phys. Chem. C 2012, 116, 24262-24267. [CrossRef] 
20. Yang, Y.B.; Dash, J.K.; Littlejohn, A.J.; Xiang, Y.; Wang, Y.; Shi, J.; Zhang, L.H.; Kisslinger, K.; Lu, T.M.; Wang, G.C. Large single crystal $\mathrm{SnS}_{2}$ flakes synthesized from coevaporation of $\mathrm{Sn}$ and S. Cryst. Growth Des. 2016, 16, 961-973. [CrossRef]

21. Laviron, E. General expression of the linear potential sweep voltammogram in the case of diffusionless electrochemical systems. J. Electroanal. Chem. Interfacial Electrochem. 1979, 101, 19-28. [CrossRef]

22. Zheng, B.Z.; Liu, G.Y.; Yao, A.W.; Xiao, Y.L.; Du, J.; Guo, Y.; Xiao, D.; Hu, Q.; Choi, M.M.F. A sensitive AgNPs/CuO nanofibers non-enzymatic glucose sensor based on electrospinning technology. Sens. Actuat. B 2014, 195, 431-438. [CrossRef]

23. Miao, Z.L.; Wang, P.Y.; Zhong, A.M.; Yang, M.F.; Xu, Q.; Hao, S.R.; Hu, X.Y. Development of a glucose biosensor based on electrodeposited gold nanoparticles-polyvinylpyrrolidone-polyaniline nanocomposites. J. Electroanal. Chem. 2015, 756, 153-160. [CrossRef]

24. Kumar-Krishnan, S.; Chakaravarthy, S.; Hernandez-Rangel, A.; Prokhorov, E.; Luna-Barcenas, G.; Esparza, R.; Meyyappan, M. Chitosan supported silver nanowires as a platform for direct electrochemistry and highly sensitive electrochemical glucose biosensing. RSC Adv. 2016, 6, 22950. [CrossRef]

25. Yu, L.Y.; Wei, X.H.; Fang, C.; Tu, Y.F. A disposable biosensor for noninvasive diabetic diagnosis rest on the $\mathrm{Au} / \mathrm{TiO}_{2}$ nano-composite intensified electrochemiluminescence. Electrochim. Acta 2016, 211, 27-35. [CrossRef]

(C) 2017 by the authors; licensee MDPI, Basel, Switzerland. This article is an open access article distributed under the terms and conditions of the Creative Commons Attribution (CC BY) license (http:/ / creativecommons.org/licenses/by/4.0/). 